\title{
Dissecting the Genetic Susceptibility to Graves' Disease in a Cohort of Patients of Italian Origin
}

\begin{abstract}
Angela Lombardi ${ }^{1 * \dagger}$, Francesca Menconi ${ }^{2 \dagger}$, David Greenberg ${ }^{3}$, Erlinda Concepcion ${ }^{1}$, Marenza Leo ${ }^{2}$, Roberto Rocchi ${ }^{2}$, Michele Marinó ${ }^{2}$, Mehdi Keddache ${ }^{4}$ and Yaron Tomer ${ }^{1,5 *}$

'Division of Endocrinology, Icahn School of Medicine at Mount Sinai, New York, NY, USA, ${ }^{2}$ Endocrinology, University Hospital of Pisa, Pisa, Italy, ${ }^{3}$ Battelle Center for Mathematical Medicine, Nationwide Children's Hospital, Columbus, OH, USA,

${ }^{4}$ Cincinnati Children's Hospital Medical Center, Cincinnati, OH, USA, ${ }^{5}$ Bronx VA Medical Center, Bronx, NY, USA
\end{abstract}

Graves' disease (GD) is an autoimmune oligogenic disorder with a strong hereditary component. Several GD susceptibility genes have been identified and confirmed during the last two decades. However, there are very few studies that evaluated susceptibility genes for GD in specific geographic subsets. Previously, we mapped a new locus on chromosome $3 q$ that was unique to GD families of Italian origin. In the present study, we used association analysis of single-nucleotide polymorphism (SNPs) at the $3 q$ locus in a cohort of GD patients of Italian origin in order to prioritize the best candidates among the known genes in this locus to choose the one(s) best supported by the association. DNA samples were genotyped using the Illumina GoldenGate genotyping assay analyzing 690 SNP in the linked $3 q$ locus covering all 124 linkage disequilibrium blocks in this locus. Candidate non-HLA (human-leukocyte-antigen) genes previously reported to be associated with GD and/or other autoimmune disorders were analyzed separately. Three SNPs in the 3q locus showed a nominal association ( $p$ < 0.05): rs13097181, rs763313, and rs6792646. Albeit these could not be further validated by multiple comparison correction, we were prioritizing candidate genes at a locus already known to harbor a GD-related gene, not hypothesis testing. Moreover, we found significant associations with the thyroidstimulating hormone receptor (TSHR) gene, the cytotoxic T-lymphocyte antigen-4 (CTLA-4) gene, and the thyroglobulin (TG) gene. In conclusion, we identified three SNPs on chromosome $3 q$ that may map a new GD susceptibility gene in this region which is unique to the Italian population. Furthermore, we confirmed that the TSHR, the CTLA-4, and the TG genes are associated with GD in Italians. Our findings highlight the influence of ethnicity and geographic variations on the genetic susceptibility to GD.

Keywords: Graves' disease, thyroid diseases, genetic predisposition to disease, SNP association study, Italian patients

\section{INTRODUCTION}

Graves' disease (GD) is one of the most common autoimmune endocrine disorders characterized by goiter, hyperthyroidism and, in 10-25\% of patients, ophthalmopathy (1,2).GDis an antibody-mediated autoimmune disease, in which the pathogenic antibodies stimulate the thyroid-stimulating hormone (thyrotropin, TSH) receptor resulting in the clinical syndrome of goiter and hyperthyroidism. The 
pathogenesis of GD involves breakdown of central and peripheral tolerance, infiltration of the thyroid with thyroid-directed T-cells that escaped tolerance, and activation of B-cells to secrete TSH receptor (TSHR) stimulating antibodies (3).

While the exact etiology of GD has not been pinpointed yet, accumulating data, mainly obtained in twin studies, support a solid genetic predisposition to the disease, although the penetrance of the genetic determinants is about $22-35 \%$ (based on monozygotic twin concordance rates) (4-6). Several GD susceptibility genes have been identified and confirmed through linkage and association studies during the last three decades, including immune regulatory genes $H L A-D R$, (human leukocyte antigen - D related) cluster of differentiation 40 (CD40), CTLA-4, protein tyrosine phosphatase non-receptor type 22 (PTPN22), interleukin-2 receptor alpha chain (CD25), and thyroid-specific genes TSHR and TG (7). Moreover, several susceptibility genes for Graves' ophthalmopathy have been proposed over the years based on small case-control association studies. These include CTLA-4, tumor necrosis factor- $\alpha(T N F-\alpha)$, intercellular adhesion molecule-1 (ICAM-1), interferon- $\gamma($ IFN- $\gamma)(8)$, insulin-like growth factor-1 receptor (IGF-1R) (9), suppressor of cytokine signaling 3 (SOCS3) (10), thyroid peroxidase (TPO) (11), calsequestrin 1 (CASQ1) (12), cysteine-rich angiogenic inducer 61 (CYR61), zinc finger protein $36 \mathrm{C} 3 \mathrm{H}$ type homog mouse (ZFP36), and stearoylcoenzyme A desaturase (SCD) (13). However, none of the Graves' ophthalmopathy specific genes have been confirmed.

Ethnicity and geographic variations influence the genetic susceptibility to GD. Previous studies demonstrated in Caucasian populations a positive and a negative association of GD with the serologically defined HLA DR3 and DR5 groups, respectively $(14,15)$. $H L A-D R B 1^{\star} 0301$ gave the highest positive predictive value for GD (15). HLA genes have been shown to be associated with GD in non-Caucasian populations as well, though the associated alleles were different from those observed in Caucasians $(7,16-18)$. For instance, the $H L A-D R B 1^{\star} 0405 / D Q B 1^{\star} 0401$ and the $D R B 3^{\star} 020 / D Q A 1^{\star} 0501$ haplotypes have been directly linked to GD in Asians (19) and in African-American (20) subjects, respectively. Notably, ethnic influences have been reported also for non-MHC genes; indeed linkage analysis in Caucasian families from different geographic regions showed different influences of the CTLA-4 gene on GD development $(21,22)$, suggesting that even within the same ethnic group, geographic variations can have a strong effect on susceptibility to disease. Similarly, a recent study indicated that genetic polymorphisms at CD25, a gene that is associated with GD in Caucasians, do not exert a significant genetic effect on the development of GD in the Chinese Han population (23). Also, significant ethnic differences in the distribution of two germline TSHR polymorphisms (P52T and D727E) were found among the Chinese, Malays, and Indians (24).

Intriguingly, epidemiological surveys from various, mostly iodine sufficient, populations have shown a relatively comparable incidence of GD across Caucasian populations in different geographic regions (approximately 20-25/100,000/year). The comparable prevalence and incidence of GD in geographically distinct Caucasian populations may indicate that these populations share at least some of their susceptibility genes for GD, albeit unique GD genes for different populations must exist too (25). Nevertheless, there are very few studies that analyzed susceptibility genes for GD in specific geographic subsets of Caucasian GD patients. We have previously performed linkage analyses in a large dataset of multiplex GD families. Within our large dataset of GD families, an Italian subset of GD families did not show linkage to the CD40 gene/locus on chromosome $20 \mathrm{q}$ in contrast to all other Caucasian populations we studied. Moreover, we mapped a new locus on chromosome $3 \mathrm{q}$ that was unique to the Italian subset of our GD families (26). These data suggest that there are unique susceptibility gene/loci within Caucasian GD patients, as determined by our subset of Italian GD families, and that distinct genes predispose to GD in different subsets of patients.

Our previous results demonstrate the importance of identifying subsets of patients within large datasets in order to map genes that may be subset-specific. Therefore, the goal of the present study was to fine map the $3 \mathrm{q}$ locus and evaluate known GD susceptibility genes in a cohort of GD patients of Italian origin.

\section{MATERIALS AND METHODS}

\section{Study Subjects}

The project was approved by the Mount Sinai School of Medicine Institutional Review Board. We analyzed Caucasian GD patients of Italian origin. GD was diagnosed by (1) documented clinical and biochemical hyperthyroidism requiring treatment and (2) presence of TSH receptor antibodies and/or diffusely increase ${ }^{131}$ I uptake in the thyroid gland.

\section{Genotyping}

DNA was extracted from whole blood using the Puregene kit (Gentra Systems, Minneapolis, MN, USA). DNA samples were genotyped using the Illumina GoldenGate genotyping assay as previously described (27). The GoldenGate single-nucleotide polymorphism (SNP) genotyping platform uses a discriminatory DNA polymerase and ligase to interrogate many SNPs simultaneously. The protocol is automated allowing high throughput and minimal errors. The GoldenGate genotyping assay utilized the BeadArray Reader. The GoldenGate assays were designed to analyze SNPs both in the linked locus on chromosome 3 and in a panel of GD candidate genes.

\section{Fine Mapping of the Chromosome 3q Locus}

The chromosome $3 \mathrm{q}$ locus spans about $14 \mathrm{Mb}$ and was fine mapped using a panel of 690 SNPs. Since the linkage analysis showed that there was a gene in the region, our goal in association mapping was to prioritize the best candidates among the known genes in this locus to choose the one(s) best supported by the association. Markers for fine mapping $3 \mathrm{q}$ were selected from the Illumina Infinium Human1M BeadChip panel leveraging the pre-selection by Illumina of markers focused on haplotype tagging and maximal allele frequency in the CEU population. The SNPs selected were sufficient to capture all alleles with an $r^{2}>0.8$. The mean max $r^{2}$ for our SNPs was 0.987. Therefore, our 690 SNPs gave more than sufficient coverage of the $3 \mathrm{q}$ locus. 
Case-control association analyses for markers within the $3 \mathrm{q}$ locus were performed using the UNPHASED computer package. ${ }^{1}$ $\operatorname{UNPHASED}(28,29)$ is a suite of programs for association analysis of multilocus haplotypes from unphased genotype data. We used the Cocaphase program (within the UNPHASED package) for case-control association analyses performing the $\chi^{2}$ test on all 690 SNPs simultaneously. The odds ratio (OR) was calculated by the method of Woolf (30).

\section{Linkage Disequilibrium Analysis}

Linkage disequilibrium (LD) analysis was performed for the $3 \mathrm{q}$ locus using the Haploview program ${ }^{2}$ using SNP genotypes from the HapMap database (31). Haplotype analysis and haplotype association analysis of SNPs rs13097181, rs7633131, and 6792646 was performed with Haploview using our Italian GD and Italian controls genotypes.

\section{Candidate Gene Analysis}

Non-HLA genes that have been previously reported to be associated with GD and/or other autoimmune disorders were analyzed separately using the $\chi^{2}$ test. These candidate genes included TSHR, TG, CTLA-4, CD40, interleukin 23 receptor (IL23R), CD25, PTPN22, forkhead box P3 (FOXP3), interferon regulatory factor 5 (IRF5), and toll-like receptor 4 (TLR4) genes (32-37).

\section{Power Calculations}

Power calculations were performed using the CDC simulation software (Epi-Info, 7.1.3.3, CDC, Atlanta) (38). We assumed the population frequency of the susceptibility SNP allele to be $\geq 10 \%$ since we tested only common variants, and we used the gamete numbers since we performed allelic associations (39). The power calculations demonstrated that our dataset of $333 \mathrm{GD}$ patients (666 chromosomes) and 117 controls (234 chromosomes) will give the study $80 \%$ power to detect a difference between the patients and the controls resulting in ORs of $\geq 2.0$ with an alpha of 0.05 . Therefore, our study was sufficiently powered to detect functionally significant differences between patients and controls.

\section{RESULTS}

\section{Characteristics of the Italian GD Population}

We studied 333 Caucasian patients with GD of Italian origin. The average age at diagnosis was $40.0 \pm 13.8$ years (range $13-75$ years), and there were 249 female and 84 male patients. The average age at ascertainment was $47.1 \pm 13.7$, and the average disease duration was 7.1 years. Additionally, 180 patients (54\%) had goiter, 154 patients (46\%) had Graves' ophthalmopathy, and in 45 patients (14\%), the ophthalmopathy status could not be confirmed. Control individuals of Italian origin $(n=117)$ had normal thyroid function, were negative for thyroid autoantibodies, and had no personal or family history of thyroid disease. There were 64 (55\%) women and 53 men (45\%). They were all over 18 years of

${ }^{1}$ http://unphased.sourceforge.net/

${ }^{2}$ http://broad.mit.edu/mpg/haploview/ age. However, the precise age at ascertainment was not available for all the controls.

\section{Fine Mapping of the Chromosome 3q Locus and Haplotype Analysis}

Figure 1 shows the results of association analyses of the 690 SNPs used to fine map the chromosome $3 \mathrm{q}$ locus that is linked with GD in patients of Italian origin. Three SNPs showed a significant association: $r$ 13097181 $\left(p=3.7 \times 10^{-3}\right.$, OR: 2.0$)$, rs7633131 $\left(p=7.7 \times 10^{-3}\right.$, OR: 1.7$)$, and $\operatorname{rs6792646}\left(p=7.8 \times 10^{-3}\right.$, OR: 1.5$)$. LD analysis showed that the $3 \mathrm{q}$ locus contained 124 LD blocks. If we were testing the hypothesis that there is a GD gene in the region, it would have been necessary to correct for multiple testing which would make the associations not significant. However, we were not testing the hypothesis of a GD gene in this locus. Rather our goal was to prioritize candidate genes at a locus already known to harbor a GD-related gene, and the $p$-values were only used to prioritize.

Haplotype analysis performed using Haploview for SNPs rs13097181, rs7633131, and rs6792646 (using either the genotypes in our cohort or the HapMap genotypes) revealed that there was no LD between these three SNPs due to the large distances between them (5.3 Mb between rs13097181 and rs7633131; $1.8 \mathrm{Mb}$ between rs7633131 and rs6792646). Therefore, no haplotypes were identified for these three SNPS, and no combination of alleles of these three SNPs was associated with GD.

\section{Candidate Gene Analysis}

Several genes have been previously reported to be associated with GD in Caucasians and other ethnic groups $(5,40)$. We investigated a panel of genes previously shown to be linked with GD as well as genes associated with other autoimmune diseases (e.g., IRF5 and TLR4, see Table 1). Among the candidate genes tested, we found associations with the TSHR gene $\left(p=3.94 \times 10^{-6}\right)$, the CTLA-4 gene $\left(p=1 \times 10^{-3}\right)$, and the TG gene $(p=0.029)$.

\section{DISCUSSION}

A strong hereditary component in the pathogenesis of GD has long been recognized $(41,42)$. The inheritance of GD is complex, involving multiple genes with variable penetrance, and environmental and epigenetic factors also play a critical role in the etiology of the disease $(5,43,44)$. Previous studies have shown differences in genetic associations with GD in different ethnic groups; however, most of these studies compared Caucasian patients to Asian patients.

In the present study, we dissected the genetic susceptibility in GD patients of Italian origin via fine mapping the Italian GD locus on chromosome $3 \mathrm{q}$ and analyzing several known susceptibility genes for GD. We identified three SNPs on chromosome $3 q$ that were associated with GD in Italian patients, and we demonstrated that the TSHR, the CTLA-4, and the TG genes are associated with GD in Italians. Our results are consistent with previous findings suggesting the existence of unique autoimmunity susceptibility genes in Caucasian populations of different geographic regions $(26,45)$. Indeed, Marron et al. have shown considerable variability 


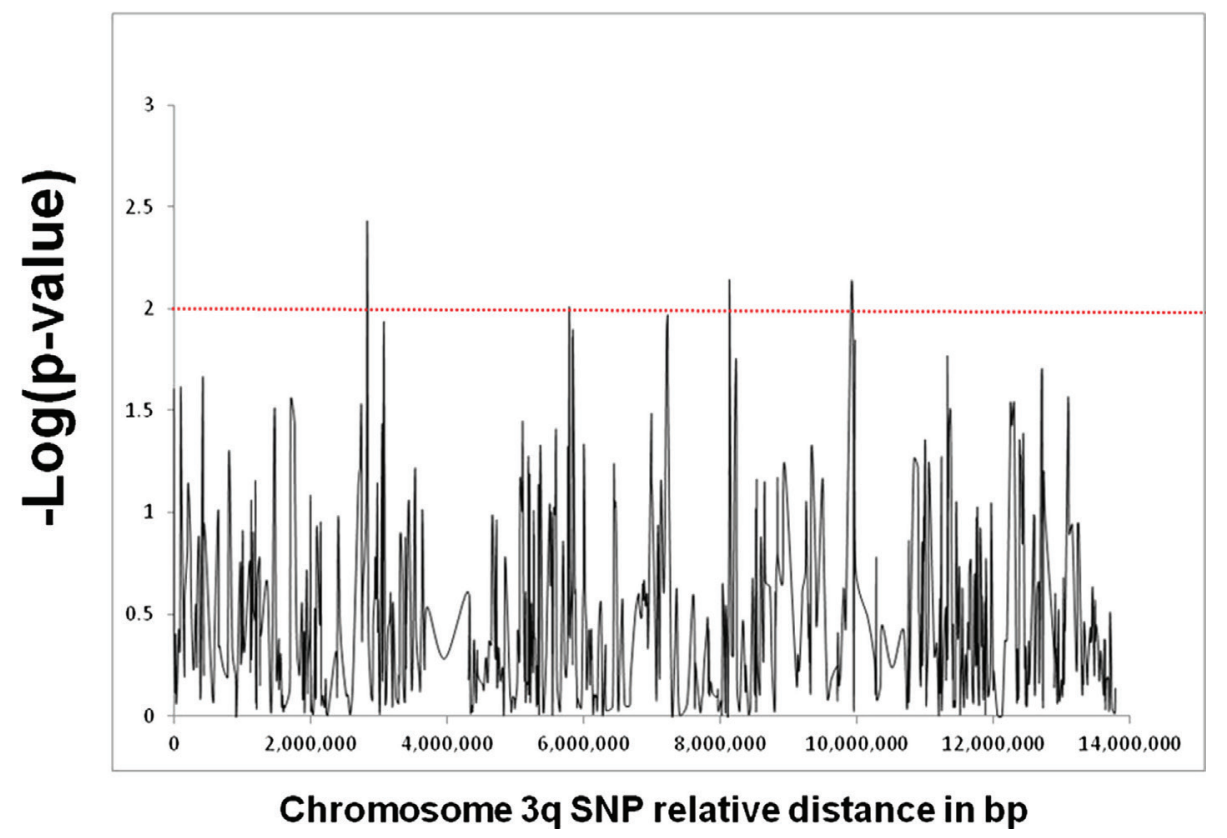

FIGURE 1 | Fine mapping analysis of the locus on chromosome $3 q$ that showed strong linkage with GD in our subset of Italian GD families. The locus spans approximately $14 \mathrm{Mb}$ and was fine mapped using a panel of 690 informative SNPs. The $X$-axis shows the distance in base pair between the SNPs and the $Y$-axis shows the -log(p-value) as computed by the UNPHASED program. The red line corresponds to a $p$-value of 0.01 . Three SNPs (rs13097181, rs7633131, and rs6792646) showed significant association with $p$-values $<0.01$.

in the association of CTLA-4 with type 1 diabetes among different Caucasian populations (46).

We tested 690 SNPs for association with GD at the $3 q$ locus, a locus which a family study had previously been identified as containing a GD-related gene. Our goal in this study was not to identify a region containing disease-related gene but to prioritize which genes might be worth pursuing. Many of the 690 SNPs we typed shared LD blocks, meaning the association signals the SNPs produced were not independent of one another. The $3 \mathrm{q}$ locus that was fine mapped contained 124 LD blocks. Correcting for multiple testing using the Bonferroni correction for 124 tests would make the $p$-values for the three associated SNPs become not significant. However, since we were within a locus that we already determined to be linked to the disease, interpreting the Bonferroni-corrected $p$-values with the same intent as for a GWAS would miss our goal of determining which genes would be the best ones to examine in the next step of identifying the diseaserelated gene. Ideally, stronger association signals ( $p$-values) would be better but the decision to investigate a specific patient population limited the sample size. Nonetheless, the results do give us important information that can be used to prioritize the known genes best supported by our association study.

The SNP within the chromosome $3 \mathrm{q}$ locus showing the strongest association with GD in Italians (rs13097181) maps to an intergenic region between the EPHB1 gene (ephrin receptor B 1) and the $K Y$ gene (kyphoscoliosis peptidase). Notably, ephrin receptors make up the largest subgroup of the receptor tyrosine kinase family and are known to regulate T-cell activation, costimulation, and proliferation $(47,48)$, suggesting a potential functional role for $E P H B 1$ in the context of GD pathogenesis. The potential role, if any, of the $K Y$ gene, generally involved in processes of muscle growth (49), in GD pathophysiology remains to be determined. The other two chromosome $3 q$ SNPs that were associated with GD in our population are rs7633131 and rs6792646. rs7633131 is an intronic SNP within the CLSTN2 gene (calsyntenin 2), which does not affect the immune system or the thyroid (50). rs6792646 is an intergenic SNP located between the GRK7 (G protein-coupled receptor kinase 7) gene and the HMGN2P25 (high mobility group nucleosomal-binding domain 2 pseudogene 25) gene, two genes that do not seem to be functionally connected to GD $(51,52)$. Of course, the assumptions on potential mechanisms linking these genes to GD deserve further experimental validation. Nonetheless, disease-associated SNPs can also impact transcriptional mechanisms by modulating the binding of transcriptional factors or long-range interactions via genetic/epigenetic dysregulation $(43,53)$, eventually upregulating or downregulating gene transcription in order to generate a phenotype (54).

Genes that exert their effect early in the autoimmune response and control the breakdown in self-tolerance are strongly associated with GD. In the past two decades, several GD susceptibility genes have been identified and confirmed through linkage and association studies, including $H L A-D R \beta 1$ Arg74, CTLA-4, PTPN22, CD40, CD25, TG, and the TSHR gene (55). $T G$, in particular, is an important candidate gene for GD, indeed the best model of human autoimmune thyroiditis is induced by immunizing mice with TG (56). Interestingly, GD patients have increased numbers of circulating $\mathrm{T}$ cells and $\mathrm{B}$ 
TABLE 1 | Results of candidate gene analysis.

\begin{tabular}{lll}
\hline Candidate gene & SNP & p-value \\
\hline IL23R & rs2201841 & 0.622036 \\
IL23R & rs11209026 & 0.259565 \\
IL23R & rs10889677 & 0.786908 \\
PTPN22 & rs2476601 & 0.727479 \\
CTLA4 & rs231775 & $\mathbf{0 . 0 0 1 0 6 8 5 2}$ \\
CTLA4 & rs3087243 & $\mathbf{0 . 0 3 0 3 2 3 3}$ \\
IRF5 & rs4728142 & 0.45456 \\
IRF5 & rs10488631 & 0.769101 \\
IRF5 & rs12537284 & 0.56248 \\
Tg & rs180194 & 0.384458 \\
Tg & rs180223 & 0.624968 \\
Tg & rs2069550 & 0.692976 \\
Tg & rs853326 & 0.754905 \\
Tg & rs2069561 & $\mathbf{0 . 0 2 9 2 3 3 1}$ \\
Tg & rs2076740 & 0.182472 \\
Tg & rs2294024 & 0.214108 \\
TLR4 & rs4986790 & 0.736433 \\
TLR4 & rs4986791 & 0.163881 \\
CD25 & rs706778 & 0.0630883 \\
CD25 & rs3118470 & 0.52791 \\
CD25 & rs41295061 & 0.498702 \\
TSHR & rs179247 & $\mathbf{3 . 9 4 E - 0 6}$ \\
TSHR & rs3783948 & $\mathbf{0 . 0 0 1 0 4 2 0 5}$ \\
TSHR & rs12101255 & $\mathbf{0 . 0 3 5 6 9 3 6}$ \\
CD40 & rs1883832 & 0.464766 \\
CD40 & rs4810485 & 0.466903 \\
FOXP3 & rs6609857 & 0.743244 \\
FOXP3 & rs2294021 & 0.703636 \\
FOXP3 & rs2280883 & 0.747625 \\
FOXP3 & FOXP3 & 0.738291 \\
\hline F & & 0.496996 \\
\hline
\end{tabular}

Genes in bold are significantly associated with $G D$.

cells that proliferate in response to stimulation with TG (57). Recently, a significant positive correlation has been reported between serum TG levels and the presence and severity of ophthalmopathy in patients with GD. In these patients, TG levels also correlated to serum titers of TSHR antibodies, indicating that not only TSHR but also TG may be released from the thyroid gland in the course of a thyroiditis and home to the orbit where they become targets of autoantibodies and cytotoxic $\mathrm{T}$ lymphocytes $(58,59)$.

Furthermore, several genetic studies have demonstrated an association between thyroid autoimmunity and gene polymorphisms of proteins and enzymes associated with vitamin D

\section{REFERENCES}

1. Hollowell JG, Staehling NW, Flanders WD, Hannon WH, Gunter EW, Spencer CA, et al. Serum TSH, T(4), and thyroid antibodies in the United States population (1988 to 1994): National Health and Nutrition Examination Survey (NHANES III). J Clin Endocrinol Metab (2002) 87(2):489-99. doi:10.1210/ jcem.87.2.8182

2. Hemminki K, Li X, Sundquist J, Sundquist K. The epidemiology of Graves' disease: evidence of a genetic and an environmental contribution. J Autoimmun (2010) 34(3):J307-13. doi:10.1016/j.jaut.2009.11.019

3. Davies TF. Trauma and pressure explain the clinical presentation of the Graves' disease triad. Thyroid (2000) 10(8):629-30. doi:10.1089/ 10507250050137680 functions (60-62). Indeed, in animal models, vitamin D administration efficiently prevented the induction of experimental autoimmune thyroiditis (63). Moreover, taking into account human studies, a high prevalence of vitamin $\mathrm{D}$ deficiency was reported both in patients with chronic autoimmune thyroiditis and in those with GD (64).

Consistent with previous reports $(5,40)$, among the candidate genes we tested, we found significant associations with the TSHR, CTLA-4, and TG genes. The CTLA-4 gene had been previously implicated, in different ethnic groups, in diverse autoimmune disorders, including Addison's disease (65), Hashimoto's thyroiditis (66), Type 1 diabetes mellitus (22), multiple sclerosis (67), and GD (68). Of note, there was no significant association of GD with CD40 in our dataset, which is in agreement with our previous finding that $C D 40$ was not linked with GD in a cohort of Italian families (69). Moreover, the TG SNP that is associated with GD in our Italian cohort is different than the one we previously identified in a cohort of North American Caucasian AITD patients, again underscoring the importance of ethnic variations in variants predisposing to GD.

The main limitation of our study is the relatively small size of our cohort. However, our cohort was ethnically homogenous, thereby increasing the power of our analysis.

In conclusion, we identified three SNPs on chromosome $3 q$ that are associated with GD in Italian patients indicating potential GD susceptibility genes in this locus. Furthermore, we demonstrated that the TSHR, the CTLA-4, and the TG genes are associated with GD in Italians. Notably, there were no associations with CD40, CD25, and FOXP3. Our findings highlight the importance of ethnic variation in the association of different polymorphisms with GD even within the same candidate gene.

\section{AUTHOR CONTRIBUTIONS}

All authors have contributed significantly to the work, have read the manuscript, attest to the validity and legitimacy of the data and its interpretation, and agree to its submission.

\section{FUNDING}

This work was supported in part by grants DK061659 and DK073681 from NIDDK. In addition, this material is based upon work supported in part by the Department of Veterans Affairs.

4. Brix TH, Christensen K, Holm NV, Harvald B, Hegedus L. A population-based study of Graves' disease in Danish twins. Clin Endocrinol (1998) 48(4):397-400. doi:10.1046/j.1365-2265.1998.00450.x

5. Marino M, Latrofa F, Menconi F, Chiovato L, Vitti P. Role of genetic and non-genetic factors in the etiology of Graves' disease. J Endocrinol Invest (2015) 38(3):283-94. doi:10.1007/s40618-014-0214-2

6. Brown RS, Lombardi A, Hasham A, Greenberg DA, Gordon J, Concepcion E, et al. Genetic analysis in young-age-of-onset Graves' disease reveals new susceptibility loci. J Clin Endocrinol Metab (2014) 99(7):E1387-91. doi:10.1210/ jc. 2013-4358

7. Jacobson EM, Huber A, Tomer Y. The HLA gene complex in thyroid autoimmunity: from epidemiology to etiology. J Autoimmun (2008) 30(1-2):58-62. doi:10.1016/j.jaut.2007.11.010 
8. Chng CL, Seah LL, Khoo DH. Ethnic differences in the clinical presentation of Graves' ophthalmopathy. Best Pract Res Clin Endocrinol Metab (2012) 26(3):249-58. doi:10.1016/j.beem.2011.10.004

9. Bahn RS. Current Insights into the pathogenesis of Graves' ophthalmopathy. Horm Metab Res (2015) 47(10):773-8. doi:10.1055/s-0035-1555762

10. Yan R, Yang J, Jiang P, Jin L, Ma J, Huang R, et al. Genetic variations in the SOCS3 gene in patients with Graves' ophthalmopathy. J Clin Pathol (2015) 68(6):448-52. doi:10.1136/jclinpath-2014-202751

11. Kus A, Szymanski K, Peeters RP, Miskiewicz P, Porcu E, Pistis G, et al. The association of thyroid peroxidase antibody risk loci with susceptibility to and phenotype of Graves' disease. Clin Endocrinol (2015) 83(4):556-62. doi:10.1111/cen.12640

12. Lahooti H, Cultrone D, Edirimanne S, Walsh JP, Delbridge L, Cregan P, et al. Novel single-nucleotide polymorphisms in the calsequestrin-1 gene are associated with Graves' ophthalmopathy and Hashimoto's thyroiditis. Clin Ophthalmol (2015) 9:1731-40. doi:10.2147/OPTH.S87972

13. Planck T, Shahida B, Sjogren M, Groop L, Hallengren B, Lantz M. Association of BTG2, CYR61, ZFP36, and SCD gene polymorphisms with Graves' disease and ophthalmopathy. Thyroid (2014) 24(7):1156-61. doi:10.1089/ thy.2013.0654

14. Farid NR, Sampson L, Noel EP, Barnard JM, Mandeville R, Larsen B, et al. A study of human leukocyte D locus related antigens in Graves' disease. J Clin Invest (1979) 63(1):108-13. doi:10.1172/JCI109263

15. Zamani M,Spaepen M, Bex M, Bouillon R, Cassiman JJ. Primaryroleof the HLA class II DRB1*0301 allele in Graves disease. Am J Med Genet (2000) 95(5):4327. doi:10.1002/1096-8628(20001218)95:5<432::AID-AJMG5>3.0.CO;2-7

16. Katsuren E, Awata T, Matsumoto C, Yamamoto K. HLA class II alleles in Japanese patients with Graves' disease: weak associations of HLA-DR and -DQ. Endocr J (1994) 41(6):599-603. doi:10.1507/endocrj.41.599

17. Gonzalez-Trevino O, Yamamoto-Furusho JK, Cutino-Moguel T, HernandezMartinez B, Rodriguez-Reyna TS, Ruiz-Morales JA, et al. HLA study on two Mexican Mestizo families with autoimmune thyroid disease. Autoimmunity (2002) 35(4):265-9. doi:10.1080/0891693021000010712

18. Maciel LM, Rodrigues SS, Dibbern RS, Navarro PA, Donadi EA. Association of the HLA-DRB1 ${ }^{*} 0301$ and HLA-DQA1 ${ }^{*} 0501$ alleles with Graves' disease in a population representing the gene contribution from several ethnic backgrounds. Thyroid (2001) 11(1):31-5. doi:10.1089/10507250150500630

19. Hashimoto K, Maruyama H, Nishiyama M, Asaba K, Ikeda Y, Takao T, et al. Susceptibility alleles and haplotypes of human leukocyte antigen DRB1, DQA1, and DQB1 in autoimmune polyglandular syndrome type III in Japanese population. Horm Res (2005) 64(5):253-60. doi:10.1159/000089293

20. Chen QY, Nadell D, Zhang XY, Kukreja A, Huang YJ, Wise J, et al. The human leukocyte antigen HLA DRB3 ${ }^{*} 020 / \mathrm{DQA1}^{*} 0501$ haplotype is associated with Graves' disease in African Americans. J Clin Endocrinol Metab (2000) 85(4):1545-9. doi:10.1210/jcem.85.4.6523

21. Reveille JD. The genetic basis of autoantibody production. Autoimmun Rev (2006) 5(6):389-98. doi:10.1016/j.autrev.2005.10.012

22. Nistico L, Buzzetti R, Pritchard LE, Van der Auwera B, Giovannini C, Bosi E, et al. The CTLA-4 gene region of chromosome $2 \mathrm{q} 33$ is linked to, and associated with, type 1 diabetes. Belgian diabetes registry. Hum Mol Genet (1996) 5(7):1075-80. doi:10.1093/hmg/5.7.1075

23. Song ZY, Liu W, Xue LQ, Pan CM, Wang HN, Gu ZH, et al. Dense mapping of IL2RA shows no association with Graves' disease in Chinese Han population. Clin Endocrinol (2013) 79(2):267-74. doi:10.1111/cen.12115

24. Ho SC, Goh SS, Khoo DH. Association of Graves' disease with intragenic polymorphism of the thyrotropin receptor gene in a cohort of Singapore patients of multi-ethnic origins. Thyroid (2003) 13(6):523-8. doi:10.1089/105072503322238773

25. Villanueva R, Tomer Y, Greenberg DA, Mao C, Concepcion ES, Tucci S, et al. Autoimmune thyroid disease susceptibility loci in a large Chinese family. Clin Endocrinol (2002) 56(1):45-51. doi:10.1046/j0300-0664.2001.01429.x

26. Tomer Y, Menconi F, Davies TF, Barbesino G, Rocchi R, Pinchera A, et al. Dissecting genetic heterogeneity in autoimmune thyroid diseases by subset analysis. J Autoimmun (2007) 29(2-3):69-77. doi:10.1016/j.jaut.2007.05.006

27. Tomer Y, Hasham A, Davies TF, Stefan M, Concepcion E, Keddache M, et al. Fine mapping of loci linked to autoimmune thyroid disease identifies novel susceptibility genes. JClin Endocrinol Metab (2013) 98(1):E144-52. doi:10.1210/jc.2012-2408
28. Dudbridge F. Likelihood-based association analysis for nuclear families and unrelated subjects with missing genotype data. Hum Hered (2008) 66(2):87-98. doi:10.1159/000119108

29. Mishima H, Lidral AC, Ni J. Application of the Linux cluster for exhaustive window haplotype analysis using the FBAT and unphased programs. $B M C$ Bioinformatics (2008) 9(Suppl 6):S10. doi:10.1186/1471-2105-9-S6-S10

30. Woolf B. On estimating the relation between blood group and disease. Ann Hum Genet (1955) 19(4):251-3. doi:10.1111/j.1469-1809.1955.tb01348.x

31. Barrett JC, Fry B, Maller J, Daly MJ. Haploview: analysis and visualization of LD and haplotype maps. Bioinformatics (2005) 21(2):263-5. doi:10.1093/ bioinformatics/bth 457

32. Brand OJ, Lowe CE, Heward JM, Franklyn JA, Cooper JD, Todd JA, et al. Association of the interleukin-2 receptor alpha (IL-2Ralpha)/CD25 gene region with Graves' disease using a multilocus test and tag SNPs. Clin Endocrinol (2007) 66(4):508-12. doi:10.1111/j.1365-2265.2007.02762.x

33. Inoue $\mathrm{N}$, Watanabe $\mathrm{M}$, Yamada $\mathrm{H}$, Takemura K, Hayashi F, Yamakawa N, et al. Associations between autoimmune thyroid disease prognosis and functional polymorphisms of susceptibility genes, CTLA4, PTPN22, CD40, FCRL3, and ZFAT, previously revealed in genome-wide association studies. JClin Immunol (2012) 32(6):1243-52. doi:10.1007/s10875-012-9721-0

34. Simmonds MJ, Brand OJ, Barrett JC, Newby PR, Franklyn JA, Gough SC. Association of Fc receptor-like 5 (FCRL5) with Graves' disease is secondary to the effect of FCRL3. Clin Endocrinol (2010) 73(5):654-60. doi:10.1111/j.1365-2265.2010.03843.x

35. Ban Y, Tozaki T, Tobe T, Ban Y, Jacobson EM, Concepcion ES, et al. The regulatory $\mathrm{T}$ cell gene FOXP3 and genetic susceptibility to thyroid autoimmunity: an association analysis in Caucasian and Japanese cohorts. J Autoimmun (2007) 28(4):201-7. doi:10.1016/j.jaut.2007.02.016

36. Graham RR, Kozyrev SV, Baechler EC, Reddy MV, Plenge RM, Bauer JW, et al. A common haplotype of interferon regulatory factor 5 (IRF5) regulates splicing and expression and is associated with increased risk of systemic lupus erythematosus. Nat Genet (2006) 38(5):550-5. doi:10.1038/ng1782

37. Xiao W, Liu Z, Lin J, Xiong C, Li J, Wu K, et al. Association of TLR4 and TLR5 gene polymorphisms with Graves' disease in Chinese Cantonese population. Hum Immunol (2014) 75(7):609-13. doi:10.1016/j.humimm.2014.05.001

38. Menconi F, Monti MC, Greenberg DA, Oashi T, Osman R, Davies TF, et al. Molecular amino acid signatures in the MHC class II peptide-binding pocket predispose to autoimmune thyroiditis in humans and in mice. Proc Natl Acad Sci U S A (2008) 105(37):14034-9. doi:10.1073/pnas.0806584105

39. Clarke GM, Anderson CA, Pettersson FH, Cardon LR, Morris AP, Zondervan KT. Basic statistical analysis in genetic case-control studies. Nat Protoc (2011) 6(2):121-33. doi:10.1038/nprot.2010.182

40. Guo T, Huo Y, Zhu W, Xu F, Liu C, Liu N, et al. Genetic association between IL-17F gene polymorphisms and the pathogenesis of Graves' disease in the Han Chinese population. Gene (2013) 512(2):300-4. doi:10.1016/j. gene.2012.10.021

41. Brix TH, Petersen HC, Iachine I, Hegedus L. Preliminary evidence of genetic anticipation in Graves' disease. Thyroid (2003) 13(5):447-51. doi:10.1089/105072503322021106

42. Prabhakar BS, Bahn RS, Smith TJ. Current perspective on the pathogenesis of Graves' disease and ophthalmopathy. Endocr Rev (2003) 24(6):802-35. doi:10.1210/er.2002-0020

43. Stefan M, Wei C, Lombardi A, Li CW, Concepcion ES, Inabnet WB III, et al. Genetic-epigenetic dysregulation of thymic TSH receptor gene expression triggers thyroid autoimmunity. Proc Natl Acad Sci U S A (2014) 111(34):12562-7. doi:10.1073/pnas.1408821111

44. Lombardi A, Inabnet WB III, Owen R, Farenholtz KE, Tomer Y. Endoplasmic reticulum stress as a novel mechanism in amiodarone-induced destructive thyroiditis. JClin Endocrinol Metab (2015) 100(1):E1-10. doi:10.1210/ jc.2014-2745

45. Petrone A, Giorgi G, Galgani A, Alemanno I, Corsello SM, Signore A, et al. CT60 single nucleotide polymorphisms of the cytotoxic T-lymphocyteassociated antigen- 4 gene region is associated with Graves' disease in an Italian population. Thyroid (2005) 15(3):232-8. doi:10.1089/thy.2005.15.232

46. Marron MP, Raffel LJ, Garchon HJ, Jacob CO, Serrano-Rios M, Martinez Larrad MT, et al. Insulin-dependent diabetes mellitus (IDDM) is associated with CTLA4 polymorphisms in multiple ethnic groups. Hum Mol Genet (1997) 6(8):1275-82. doi:10.1093/hmg/6.8.1275 
47. Kawano H, Katayama Y, Minagawa K, Shimoyama M, Henkemeyer M, Matsui T. A novel feedback mechanism by ephrin-B1/B2 in T-cell activation involves a concentration-dependent switch from costimulation to inhibition. Eur J Immunol (2012) 42(6):1562-72. doi:10.1002/eji.201142175

48. Luo H, Charpentier T, Wang X, Qi S, Han B, Wu T, et al. Efnb1 and Efnb2 proteins regulate thymocyte development, peripheral $\mathrm{T}$ cell differentiation, and antiviral immune responses and are essential for interleukin-6 (IL-6) signaling. J Biol Chem (2011) 286(48):41135-52. doi:10.1074/jbc.M111.302596

49. Miao Y, Yang J, Xu Z, Jing L, Zhao S, Li X. RNA sequencing identifies upregulated kyphoscoliosis peptidase and phosphatidic acid signaling pathways in muscle hypertrophy generated by transgenic expression of myostatin propeptide. Int J Mol Sci (2015) 16(4):7976-94. doi:10.3390/ijms16047976

50. Papassotiropoulos A, Stephan DA, Huentelman MJ, Hoerndli FJ, Craig DW, Pearson JV, et al. Common Kibra alleles are associated with human memory performance. Science (2006) 314(5798):475-8. doi:10.1126/science.1129837

51. Daniele S, Trincavelli ML, Fumagalli M, Zappelli E, Lecca D, Bonfanti E, et al. Does GRK-beta arrestin machinery work as a "switch on" for GPR17mediated activation of intracellular signaling pathways? Cell Signal (2014) 26(6):1310-25. doi:10.1016/j.cellsig.2014.02.016

52. Su L, Hu A, Luo Y, Zhou W, Zhang P, Feng Y. HMGN2, a new antitumor effector molecule of CD8(+) T cells. Mol Cancer (2014) 13:178. doi:10.1186/1476-4598-13-178

53. Davison LJ, Wallace C, Cooper JD, Cope NF, Wilson NK, Smyth DJ, et al. Long-range DNA looping and gene expression analyses identify DEXI as an autoimmune disease candidate gene. Hum Mol Genet (2012) 21(2):322-33. doi: $10.1093 / \mathrm{hmg} / \mathrm{ddr} 468$

54. Kilpinen H, Waszak SM, Gschwind AR, Raghav SK, Witwicki RM, Orioli A, et al. Coordinated effects of sequence variation on DNA binding, chromatin structure, and transcription. Science (2013) 342(6159):744-7. doi:10.1126/ science. 1242463

55. Huber AK, Jacobson EM, Jazdzewski K, Concepcion ES, Tomer Y. Interleukin (IL)-23 receptor is a major susceptibility gene for Graves' ophthalmopathy: the IL-23/T-helper 17 axis extends to thyroid autoimmunity. J Clin Endocrinol Metab (2008) 93(3):1077-81. doi:10.1210/jc.2007-2190

56. Charreire J. Immune mechanisms in autoimmune thyroiditis. Adv Immunol (1989) 46:263-334. doi:10.1016/S0065-2776(08)60656-2

57. Nielsen CH, Moeller AC, Hegedus L, Bendtzen K, Leslie RG. Self-reactive $\mathrm{CD} 4+\mathrm{T}$ cells and $\mathrm{B}$ cells in the blood in health and autoimmune disease: increased frequency of thyroglobulin-reactive cells in Graves' disease. J Clin Immunol (2006) 26(2):126-37. doi:10.1007/s10875-006-9000-Z

58. Shanmuganathan T, Girgis C, Lahooti H, Champion B, Wall JR. Does autoimmunity against thyroglobulin play a role in the pathogenesis of Graves' ophthalmopathy: a review. Clin Ophthalmol (2015) 9:2271-6. doi:10.2147/ OPTH.S88444

59. Marino M, Chiovato L, Lisi S, Altea MA, Marcocci C, Pinchera A. Role of thyroglobulin in the pathogenesis of Graves' ophthalmopathy: the hypothesis of Kriss revisited. J Endocrinol Invest (2004) 27(3):230-6. doi:10.1007/BF03345271

60. Ban Y, Taniyama M, Ban Y. Vitamin D receptor gene polymorphism is associated with Graves' disease in the Japanese population.J Clin Endocrinol Metab (2000) 85(12):4639-43. doi:10.1210/jcem.85.12.7038

61. Feng M, Li H, Chen SF, Li WF, Zhang FB. Polymorphisms in the vitamin $\mathrm{D}$ receptor gene and risk of autoimmune thyroid diseases: a meta-analysis. Endocrine (2013) 43(2):318-26. doi:10.1007/s12020-012-9812-y

62. Kurylowicz A, Ramos-Lopez E, Bednarczuk T, Badenhoop K. Vitamin D-binding protein (DBP) gene polymorphism is associated with Graves' disease and the vitamin D status in a Polish population study. Exp Clin Endocrinol Diabetes (2006) 114(6):329-35. doi:10.1055/s-2006-924256

63. D'Aurizio F, Villalta D, Metus P, Doretto P, Tozzoli R. Is vitamin D a player or not in the pathophysiology of autoimmune thyroid diseases? Autoimmun Rev (2015) 14(5):363-9. doi:10.1016/j.autrev.2014.10.008

64. Rotondi M, Chiovato L. Vitamin D deficiency in patients with Graves' disease: probably something more than a casual association. Endocrine (2013) 43(1):3-5. doi:10.1007/s12020-012-9776-y

65. Vaidya B, Imrie H, Geatch DR, Perros P, Ball SG, Baylis PH, et al. Association analysis of the cytotoxic T lymphocyte antigen-4 (CTLA-4) and autoimmune regulator-1 (AIRE-1) genes in sporadic autoimmune Addison's disease. J Clin Endocrinol Metab (2000) 85(2):688-91. doi:10.1210/jcem.85.2.6369

66. Chistiakov DA, Turakulov RI. CTLA-4 and its role in autoimmune thyroid disease. J Mol Endocrinol (2003) 31(1):21-36. doi:10.1677/jme.0.0310021

67. Liu J, Zhang HX. CTLA-4 gene and the susceptibility of multiple sclerosis: an updated meta-analysis study including 12,916 cases and 15,455 controls. J Neurogenet (2014) 28(1-2):153-63. doi:10.3109/01677063.2014.880703

68. Yanagawa T, Hidaka Y, Guimaraes V, Soliman M, DeGroot LJ. CTLA-4 gene polymorphism associated with Graves' disease in a Caucasian population. J Clin Endocrinol Metab (1995) 80(1):41-5. doi:10.1210/jcem.80.1.7829637

69. Tomer Y, Concepcion E, Greenberg DA. A C/T single-nucleotide polymorphism in the region of the CD40 gene is associated with Graves' disease. Thyroid (2002) 12(12):1129-35. doi:10.1089/105072502321085234

Conflict of Interest Statement: The authors declare that the research was conducted in the absence of any commercial or financial relationships that could be construed as a potential conflict of interest.

Copyright (C) 2016 Lombardi, Menconi, Greenberg, Concepcion, Leo, Rocchi, Marinó, Keddache and Tomer. This is an open-access article distributed under the terms of the Creative Commons Attribution License (CC BY). The use, distribution or reproduction in other forums is permitted, provided the original author(s) or licensor are credited and that the original publication in this journal is cited, in accordance with accepted academic practice. No use, distribution or reproduction is permitted which does not comply with these terms. 